\title{
Cultural influences on the developing semantic lexicon
}

\author{
Karla McGREGOR ${ }^{1,2 \star}$, Natalie MUNRO ${ }^{1}$, Su Mei CHEN ${ }^{2}$, Elise BAKER ${ }^{1}$, and Jacob OLESON ${ }^{2}$ \\ ${ }^{1}$ Faculty of Health Sciences, The University of Sydney, Australia and ${ }^{2}$ The University of Iowa, IA, USA \\ ${ }^{*}$ Corresponding author: Karla McGregor, Senior Scientist, Center for Childhood Deafness, Language \& \\ Learning, Boys Town National Research Hospital, 555 North 30th St., Omaha, NE 68131. Tel: +1 319-338- \\ 5213; E-mail: karla-mcgregor@uiowa.edu
}

(Received 7 December 2017; revised 7 April 2018; accepted 11 May 2018; first published online 2 July 2018)

\begin{abstract}
To determine whether the developing semantic lexicon varies with culture, we examined the animal and food naming of children from three communities distinguished by language, cultural heritage, and population density. The children were five- and sevenyear-olds from Australia $(n=197)$, Taiwan $(n=456)$, and the US $(n=172)$. Naming patterns revealed hierarchical and flexible organization of the semantic lexicon. The content of the lexicon, particularly food names, varied with cultural heritage. In all three communities, wild mammals were predominant during animal naming, a likely influence of children's media. The influence of the Chinese zodiac was evident in the clustering of animal names in the Taiwanese sample. There was no apparent influence of population density and little influence of language, except that the Taiwanese children more frequently named foods at the superordinate level, a possible influence of the structure of Mandarin. Children develop their lexicons in response to culture as experienced first-hand or through media.
\end{abstract}

\section{Introduction}

We take as our starting point the uncontroversial thesis that the semantic lexicon develops in response to experiences that the child accrues while immersed in and interacting with the systems of her culture. Culture is a dynamic, synergistic set of systems that include language, artifacts, practices, beliefs, values, and ways of thinking and behaving that are held more or less in common by members of a given community (Ojalehto \& Medin, 2015). Cultures can be defined at global, national, and regional levels and characterized by multiple dimensions including age, gender, religion, education, and socioeconomic status (Ojalehto \& Medin, 2015). Cultural variation affects not only the number of words children learn (Hart \& Risley, 1995; Hoff, 2006; White, Graves, \& Slater, 1990), but also the specific content and structure of the developing lexicon. In this paper, we consider the former but focus on the latter. 
Much that we know about cultural influences on the structure of the developing lexicon comes from application of the semantic fluency task. The participant is given a category label and is asked to name as many items as possible that fit that category within one minute. Depending on the question of interest, the label will index a taxonomic category, such as animal or clothing, or a slot-filler category such as animals at the zoo or clothing that is worn in cold weather (Nelson \& Nelson, 1990). The number of items named reflects, in part, the number of words known in that category (Ruff, Light, Parker, \& Levin, 1997). The first or most frequently named items reveal the exemplars that are prototypical to the category (Kail \& Nippold, 1984). The co-occurrence, proximity, or temporal clustering of items evinces semantic neighborhood structure (Winkler-Rhoades, Medin, Waxman, Woodring, \& Ross, 2010).

Cultural differences have been reported for number of items named (Williams, Terry, \& Metzger, 2013), items named most frequently (Pekkala, Goral, Hyun, Obler, Erkinjuntti, \& Albert, 2009; Peña, Bedore, \& Zlatic-Giunta, 2002), and items clustered (Taverna, Waxman, Medin, Moscoloni, \& Peralta, 2014; Winkler-Rhoades et al., 2010). Winkler-Rhoades et al. (2010) collected semantic fluency data from children and adults in urban, rural, and Native cultures in the US and found a similar preponderance of mammal names, and a similar clustering of animals by habitat (e.g., farm animals, household pets) in the three cultures; both tendencies were previously documented in other cultures (Crowe and Prescott, 2003; Lucariello, Kyratzis, \& Nelson, 1992). They also found some interesting differences. Relative to the other two samples, the urban sample (and the youngest samples) included more exotic animals than native animals whereas the Native sample (and the adult samples) included more native than exotic animals. The authors attribute this to cultural and developmental differences in daily experiences. Culturally, the participants who were Native Americans had more contact with native species because hunting and fishing were common experiences for them. Developmentally, younger children had more contact with non-native species because children's books and movies, many of which feature exotic animal characters, were common experiences for them.

Taverna et al. (2014) asked Argentine children aged five to fourteen to name living things. All children named more animals than plants, and mammals were the predominant type of animal. Children from an urban community named more exotic animals; children from a rural community named more farm animals; and children from a native Amerindian community named more forest animals. These differences reflected the distinct daily experiences of the children. The children from the urban and rural communities spoke Spanish whereas the children from the Amerindian community spoke Wichí. Although the Spanish speakers tended to list human as a living thing, the Wichí speakers never did, a difference attributable to different naming patterns in the two languages. Specifically, in Wichí, humans are rarely named as a distinct category from other living things by either children or adults.

In the present study, we build on findings such as these by comparing semantic fluency responses collected from five- and seven-year-old children in Australia, Taiwan, and the US. The languages sampled were Australian English, Taiwanese Mandarin, and American English. The communities sampled were Sydney Australia, a metropolis of roughly 4 million people, Taichung City and Taipei City Taiwan, metropolitan areas of roughly 2.7 million people each, and Iowa City US, a small city of 75,000 located in a state where farms comprise over $85 \%$ of the available land. 
The Australian and US populations are more similar to each other in language and other aspects of culture than either of these two Western populations are to the Taiwanese population. In contrast, the particular communities we sampled in Australian and Taiwan are more similar to each other in population density than either of these are to the US community we sampled. Thus, a triangulation strategy (Ross, Medin, Coley, \& Atran, 2003; Taverna et al., 2014) allowed conclusions about the relative contribution of cultural systems and daily activities to the children's semantic lexicons.

\section{Animal names}

Like Winkler-Rhoades et al. (2010) we elicited semantic fluency responses to the category animal. The three communities that we sampled have some native animals in common and others that are unique. The children in the US sample, being surrounded by farmland, likely had more direct contact with animals than the children in the Australian and Taiwanese sample but children in all three communities likely had access to books and other media about animals. More than half of 1,074 English-language children's picture-books reviewed by Marriott (2002) contained animals or animal habitats, and over 60 different species were represented. This phenomenon is not limited to picture-books. Freebody and Baker (1985) analyzed the content of basal and supplementary reading books for first- and second-graders in Australia and found that five of the top ten most common nouns referring to animate beings were the animals cat, dog, pig, fish, and bear.

Many parents in mainstream Western cultures value children's picture-books as a way to teach preliteracy skills and stimulate enthusiasm for reading (Foy \& Mann, 2003). The same is increasingly true of practices in Eastern cultures. Taiwanese parents begin to read books to their children when they are one or two years old (Wu \& Honig, 2010). In both Taiwan and the US, parents and teachers of children in preschool and early elementary school tend to select picture- and story-books with a clear narrative line rather than informational books (Wu \& Honig, 2010). There is likely an overlap between these Western and Eastern cultures in the books themselves given that an estimated $90 \%$ of books marketed for Taiwanese children are imported, mostly from the US, Europe, and Japan (Chung, 2011). Children's media is a rich source of indirect experiences with animals and, to the extent that children's media is universally available, cultural variations in animal knowledge will be minimal.

\section{Food names}

Unlike Winkler-Rhoades et al. (2010) and Taverna et al. (2014), we also elicited semantic fluency responses to the category food. Mealtimes have been the focus of much research on event-based language learning (e.g., Beals, 1997; Hoff \& Naigles, 2002; Snow \& Beals, 2006). Although it is highly likely that children learn food names from direct participation in these events, there is little documentation. We do know that children's ability to name flavors (e.g., lemon, cinnamon, coconut), an aspect of food knowledge that is necessarily learned via direct experience, increases between three and seven years (Lumeng, Zuckerman, Cardinal, \& Kaciroti, 2005).

Some mealtime events have particular cultural significance. In their review of the English-language literature on family routines and rituals, Fiese, Tomcho, Douglas, 
Josephs, Poltrock, and Baker (2002) found the most often mentioned rituals to be birthdays, funerals, family reunions, Sunday dinner, and the holidays Christmas, Thanksgiving, Easter, and Passover. Abundant and specific types of food are central to each of these. By age three, children are aware of the events that typically include food and they have some knowledge of which foods are typically eaten together (Mura Paroche, Caton, Vereijken, Weenen, \& Houston-Price, 2017).

If food names are learned from direct, routinized, culturally specific experiences, we should find differences between the food naming responses of children in our three samples, particularly between children who experience Western diets and cultural rituals and those who experience Eastern diets and cultural rituals. Peña et al. (2002) found that Spanish-English speaking four- to seven-year-olds in the United States gave largely different lists of items in response to the food category prompt in Spanish and English. Also, typicality differences were evident in that the three most frequently named items in each language were not synonymous. The children most often listed apple, banana, and hamburger when naming foods in English, but hamburguesa 'hamburger', manzana 'apple', and sopa 'soup' when naming in Spanish (Pena et al., 2002, p. 946). These differences reflect the different cultural contexts in which the children learn and use Spanish (e.g., with family) and English (e.g., at school).

\section{How animal and food names are expressed in English and Mandarin}

A comparison of English and Mandarin speakers was of particular interest because of documented variations in the development of their semantic lexicons. Lin, Schwanenflugel, and Wisenbaker (1990) asked adults and children from Taiwan and the US to rate the familiarity and typicality of items from categories like birds and fruit. In both cultures, correlations between child and adult typicality ratings increased between kindergarten and sixth grade, whereas the correlation between child familiarity and typicality ratings decreased. That is, compared to adults and older children, younger children depended more heavily on their direct everyday experiences as a basis for structuring taxonomic category relations. However, Lin et al. (1990) found the Taiwanese children to exhibit an earlier shift towards adult-like taxonomic category structure than the US children. As one potential explanation, they noted that Mandarin Chinese provides more information about category structure than English. Compound nouns are very frequent in Mandarin (Packard, 2000), thus the category name (the head of the compound) is specified in the full name. This sometimes happens in English - in bluebird and sunflower, for example - but it is much rarer than in Mandarin. For instance, whereas English has bison, buffalo, cow, ox, yak, dairy cattle, bull, and calf, all of these words for bovines in Mandarin end with niu2 'cow'. Experience with the Mandarin language itself might hasten the maturation of lexical-semantic category structure.

\section{Aims and predictions}

Our primary aim was to determine whether and how the content and structure of the developing semantic lexicon varies between cultures. We examined how children from three communities distinguished by language (English-Mandarin), cultural beliefs and practices (West-East), and population density (Metropolitan-Urban) name animals and foods in a semantic fluency task. The task is used for two primary purposes. In 
neuropsychological testing, the ability to avoid repetitions and to switch from cluster to cluster is quantified as evidence of executive function (Kavé, Kigel, \& Kochva, 2008; Koren, Kofman, \& Berger, 2005; Raboutet, Sauzéon, Corsini, Rodrigues, Langevin, \& N'Kaoua, 2010). We, instead, used the task for a second purpose, as a window onto the semantic lexicon (Hurks, Schrans, Meijs, Wassenberg, Feron, \& Jolles, 2010; Marshall, Rowley, Mason, Herman, \& Morgan, 2013; Nash \& Snowling, 2008). The predictions follow.

Because young children tend to learn about animals from media but food from direct experience, there will be more cultural overlap in animal naming than food naming. That said, our triangulation approach could reveal nuances:

- Because the children in the US sample were from a small urban area surrounded by farmland, they were likely to have more direct experience with animals than were the children in the Taiwanese and Australian samples collected in densely populated metropolitan areas. Therefore, within animal naming, we predicted variation related to population density.

- Because the children in the Taiwanese sample had Eastern diets, they were likely to have different direct experiences with food than the children in the Australian and US samples, who had Western diets. Therefore, within food naming, we predicted variation related to cultural heritage.

Because of the scaffolding of hierarchical relations provided by the structure of Mandarin, we predicted more superordinate naming and more sophisticated hierarchical structures in the responses of the Taiwanese children than in the responses of the Australian or US children. We expected this result for both the animal and food categories.

We also explored variation associated with age. It could be that cultural approaches to schooling, especially in Western vs. Eastern cultures, differ greatly and thereby yield a widening of differences in lexical-semantic content from five years to seven years of age. Alternatively, it could be that differences in lexical-semantic content narrow from five years to seven years of age as children come to know other children from various cultures who attend their school and as formal instruction introduces a broad range of leveling experiences that support word learning. Comparisons of the names listed by five-year-olds and seven-year-olds allowed a test of these alternatives.

\section{Method}

\section{Participants}

Participants were from three communities (Table 1): 197 five-, six-, and seven-year-olds were primary speakers of Australian English from Sydney Australia; 456 five- and seven-year-olds were primary speakers of Taiwanese Mandarin from Taichung City and Taipei City Taiwan; 172 five- and seven-year-olds were primary speakers of American English from Iowa City in the US. An analysis of the cluster switch behavior of the Australian participants appears in Chami et al., 2018. A comparison of the five- and seven-year-old Taiwanese participants to three-year-old Taiwanese participants appears in Chen (2012).

Our primary goal was to compare responses from the three different cultures. A secondary goal was to determine whether similarities between cultures change over the first two years of formal schooling. Therefore, for analyses that could be 
Table 1. Number, Sex, and Age of Participants by Culture

\begin{tabular}{lcccccc}
\hline Culture & $\mathrm{n}$ & Female & Male & $\begin{array}{c}\text { Age } \\
\text { (years) }\end{array}$ & $\begin{array}{c}\text { Mean age } \\
\text { (months) }\end{array}$ & $\begin{array}{c}\text { SD } \\
\text { (months) }\end{array}$ \\
\hline Australia & 67 & 30 & 37 & 5 & 67 & 3.81 \\
\hline & 64 & 35 & 29 & 6 & 78 & 4.14 \\
\hline Taiwan & 212 & 105 & 107 & 5 & 89 & 4.88 \\
\hline & 241 & 120 & 121 & 7 & 65 & 3.02 \\
\hline US & 89 & 47 & 42 & 5 & 67 & 3.42 \\
\hline & 83 & 37 & 46 & 7 & 89 & 3.54 \\
\hline
\end{tabular}

conducted with smaller samples (number of correct responses, most frequent responses, and first responses) we compared cultures at age five and at age seven. We excluded the six-year-old Australians but the comparable analyses of their data appear in a supplementary appendix (available at <https://doi.org/10.1017/S0305000918000211>) for the sake of completeness. For two analyses that required larger data sets (discovery of unique responses and cluster behavior), we again compared cultures but collapsed over all ages, including the data from the six-year-olds, to maximize sample sizes.

\section{Procedure}

Each child was seen individually at a daycare, school, or community center. In a demonstration trial, the child was asked to produce as many words as possible in the category body parts in 30 seconds. If the children failed to provide any words, the experimenter prompted by pointing to a specific body part or giving examples. Afterwards, the child was asked to produce as many words as possible in two categories, animals and food, within two 1-minute intervals. Category order was counterbalanced across participants. All data collection and data management followed approved procedures for the protection of human subjects at either the University of Iowa (US and Taiwanese samples) or the University of Sydney (Australian sample).

\section{Analysis}

The examiner wrote and audio-recorded the children's responses. Afterwards, all responses were entered into a spreadsheet and then coded for order of response and errors. Errors were of two types, out-of-category responses (e.g., plant in animal or eat in food) and repetitions of a previous response. For food we operationalized out-of-category to include things that one could ingest but that are not really food (e.g., tablets, grass) and the names of meals (e.g., lunch) and restaurants (e.g., McDonalds). We accepted beverages (e.g., milk) as correct food responses. The animal out-of-category responses included cartoon or story-book animals (e.g., Sponge Bob, Big Bad Wolf); however, we did accept creatures that were mythical (e.g., unicorn) or extinct (e.g., Tyrannosaurus Rex). To avoid underestimation of repetition errors, we took singular-plural variants (e.g., grape, grapes) and synonyms (e.g., snake, serpent) to be the same word. But we were conservative as to what counted as 
a synonym: we never collapsed age variants (e.g., deer, fawn); gender variants (e.g., lion, lioness), or taxonomic variants (e.g., fruit, grape, green grape). To ensure that rare items were correctly classified, coders used on-line dictionaries to verify inclusion in the category under consideration.

Twenty percent of data from each age group per culture was randomly extracted and coded by a second examiner from the same cultural/language environment to determine agreement on classification of responses as correct or incorrect. In all cases, point-to-point agreement exceeded 90\%.

To enable comparison between cultures, differences in language and dialect had to be resolved. The third author, a graduate student living in Iowa City who had collected the Taiwanese sample, and who is a native speaker of Taiwanese Mandarin and a fluent speaker of American English, transcribed all Mandarin responses into American English, thus enabling comparison between the Taiwanese and US samples. The first author, then a professor living in Iowa City who is a native speaker of American English and who has spent extensive time in Sydney, identified instances where American and Australian English involved different words for the same item (e.g., candy vs. lolly; pepper vs. capsicum), thus enabling comparison of the Taiwanese and US samples to the Australian sample.

Following these data-entry and coding procedures, we used Excel spreadsheet functions to determine number of correct responses, the variety of first responses, the ten most frequent responses, and the unique responses per category, age, and culture.

To ascertain the relations between items in a given category, animals or food, we used hierarchical cluster analysis via the ICLUST function (Revelle, 1979) in the psych library (Revelle, 2017) of the statistical computing language R (R Core Team, 2016). The data analyzed were all names listed by at least $20 \%$ of participants in a given culture for a given semantic category. As in a traditional factor analysis, each item loads on to, at most, a single cluster. Items that load on a given cluster are correlated, with higher correlations approaching a maximum of 1 . Items that define different clusters can negatively correlate; a negative loading means that the item has a characteristic that is opposite of that cluster and is not strongly related to any of the items that formed that cluster.

The ICLUST function also identifies hierarchical relations between clusters. The algorithm combines clusters into one higher-level cluster if that combination of clusters increases the reliability (Cronbach's coefficient of alpha, $\alpha$ ) and the size of the general factor (Revelle's beta, $\beta$ ). This algorithmic approach is ideal for the current dataset given that semantic categories exhibit a nested, hierarchical structure. For example, within the broad category animal, poodle is nested in dog which is nested in canine, which is nested in mammal. ICLUST allowed us to capture this hierarchical structure. The overall result of the ICLUST analysis is a description of the animal lexicon and the food lexicon that is shared among five- to seven-year-old members of the communities we sampled.

\section{Results}

\section{Animals}

A between-subjects ANOVA with number of correct animal responses as the dependent variable and culture and age as the independent variables revealed a main effect of age 
$(\mathrm{F}(1,749)=207.49, p<.0001, d=1.0)$, a large effect. The 367 five-year-olds who participated averaged 8.28 animal names $(\mathrm{SD}=3.08)$ whereas the 388 seven-year-olds averaged $12.37(\mathrm{SD}=4.04)$. There was neither a main effect of culture $(\mathrm{F}(2,749)=$ $2.53, p=.08)$ nor a culture $\times$ age interaction $(\mathrm{F}(2,749)=1.23, p=.29)$.

The ten most frequently named animals by culture appear in Table 2. At age five years, the top ten were exclusively mammals for all three cultures. The majority were wild mammals; however, dog and cat, which are common household pets in all three cultures, also made the list. Despite living in a heavily agricultural state, there was no evidence that the US children considered farm animals to be prototypical. One farm animal was among the top ten in the US sample, three in the Australian sample, and zero in the Taiwanese sample. At age seven years, mammals continued to predominate, but bird and fish (Australian and US samples), crocodile (Australian sample), and snake (Taiwanese sample) now made the top ten as well. There were no farm animals among the top ten in any sample at age seven. At age five years, the overlap between cultures in top ten items was $70 \%$ for Australia and Taiwan, $80 \%$ for Australia and the US, and $80 \%$ for Taiwan and the US. At age seven years, the overlap between cultures in the top ten items was $70 \%$ for Australia and Taiwan, 90\% for Australia and the US, and 70\% for Taiwan and the US.

Tables 3 and 4 list the children's first responses by culture. Although the list is highly variable, mammals again predominated and wild mammals were particularly popular. At age five years, the percentage of children whose first responses were mammals equaled $86 \%$ for Australia, $>82 \%$ for Taiwan, and $91 \%$ for the US. In all three cultures, the top three most frequent first responses were wild mammals. At age seven years, mammals continued to predominate with $88 \%,>81 \%$, and $89 \%$ of children responding first with a mammal name in the Australian, Taiwanese, and US samples, respectively.

Table 5 specifies animals that were unique to a given culture. In some cases, these are native species (e.g., wombat in Australia and Formosan sika deer in Taiwan) that do not live in the other two communities. In other cases, what was unique was the precision of specification. For example, deer occurred in samples from all three cultures, but buck occurred only in the US sample. Others that follow this pattern are bug/cicada, cow/ dairy cow, and fish/catfish, to name only a few.

The results of the ICLUST analysis appear in Figures 1-3. There were 17 clusters in the Australian sample, 14 in the Taiwanese sample, and 13 in the US sample. Comparison of the three figures reveals several commonalities. First, children in all three cultures represented semantic relations between animals in a hierarchical manner. For example, in the Australian sample, cluster 13 (C13) incorporated $\mathrm{C} 10$ and C8; in the Taiwanese sample, C8 incorporated C7 and C4; and in the US sample, C8 incorporated C2 and the single item zebra. Second, children in all three cultures organized animal neighbors by shared habitats (e.g., farm, forest, and household), as well as by taxon (e.g., the felines lion and tiger). A final commonality was that each cultural group demonstrated distinctions between items that are unrelated (i.e., negatively correlated, as depicted by the dotted lines). As a group, Australian children eschewed a relationship between rabbit and cheetah; Taiwanese children considered bird and fish to be different from giraffe and elephant; and US children considered monkey and deer to be disparate.

The most complex hierarchical structure in evidence was that headed by $\mathrm{C} 13$ in the Taiwanese results (Figure 2). This super-cluster of nine items included eight of the 12 animals in the Chinese zodiac (dog, snake, horse, rabbit, monkey, sheep/goat, cow/oxen, 
Table 2. Ten Most Frequent Animal Responses of Five- and Seven-year-olds by Culture and Percentage of Respondents

\begin{tabular}{|c|c|c|c|c|c|c|}
\hline \multicolumn{2}{|l|}{ Australia } & \multicolumn{3}{|l|}{ Taiwan } & \multicolumn{2}{|l|}{ US } \\
\hline \multicolumn{7}{|c|}{ Five-year-olds } \\
\hline lion & $55 \%$ & 長頸鹿 & giraffe & $67 \%$ & lion & $59 \%$ \\
\hline tiger & $54 \%$ & 大象 & elephant & $63 \%$ & tiger & $55 \%$ \\
\hline giraffe & $46 \%$ & 獅子 & lion & $62 \%$ & dog & $40 \%$ \\
\hline elephant & $45 \%$ & 老虎 & tiger & $48 \%$ & elephant & $40 \%$ \\
\hline zebra & $34 \%$ & 兔子 & rabbit & $33 \%$ & giraffe & $38 \%$ \\
\hline cat & $27 \%$ & 猴子 & monkey & $27 \%$ & zebra & $36 \%$ \\
\hline dog & $27 \%$ & 狗/大狗/狗狗 & dog & $26 \%$ & cat & $30 \%$ \\
\hline horse & $24 \%$ & 斑馬 & zebra & $26 \%$ & monkey & $30 \%$ \\
\hline cow & $21 \%$ & 貓/貓咪/小貓咪 & cat & $25 \%$ & bear & $27 \%$ \\
\hline pig & $21 \%$ & 河馬 & hippo & $21 \%$ & horse & $27 \%$ \\
\hline \multicolumn{7}{|c|}{ Seven-year-olds } \\
\hline lion & $66 \%$ & 獅子 & lion & $72 \%$ & dog & $76 \%$ \\
\hline tiger & $65 \%$ & 老虎 & tiger & $59 \%$ & cat & $72 \%$ \\
\hline cat & $55 \%$ & 大象 & elephant & $58 \%$ & lion & $63 \%$ \\
\hline dog & $54 \%$ & 長頸鹿 & giraffe & $55 \%$ & tiger & $52 \%$ \\
\hline elephant & $52 \%$ & 猴子 & monkey & $55 \%$ & bird & $42 \%$ \\
\hline fish & $43 \%$ & 兔/兔子 & rabbit & $50 \%$ & elephant & $42 \%$ \\
\hline monkey & $43 \%$ & 狗 & dog & $40 \%$ & giraffe & $40 \%$ \\
\hline giraffe & $42 \%$ & 貓/貓咪/喵咪 & cat & $44 \%$ & fish & $37 \%$ \\
\hline bird & $38 \%$ & 鼠/老鼠/小種的鼠 & mouse & $33 \%$ & monkey & $35 \%$ \\
\hline crocodile & $32 \%$ & 蛇/大蛇 & snake & $31 \%$ & cheetah & $34 \%$ \\
\hline
\end{tabular}

and mouse/rat). This particular basis for clustering was the sole cultural difference evident in the ICLUST outcomes.

\section{Food}

A between-subjects ANOVA with number of correct food responses as the dependent variable and culture and age as the independent variables revealed a main effect of age $(\mathrm{F}(1,746)=143.13, p<.0001, d=0.81)$, a large effect. The 364 five-year-olds who participated averaged 7.7 food names $(\mathrm{SD}=2.97)$, whereas the 388 seven-year-olds averaged $11.11(\mathrm{SD}=4.23)$. There was also a main effect of culture $(\mathrm{F}(2,746)=10.76$, $p=.00003$ ). A post-hoc HSD for unequal Ns revealed that the children from the US listed more foods $(\mathrm{M}=10.44, \mathrm{SD}=4.5)$ than the children from Taiwan $(\mathrm{M}=9.10$, $\mathrm{SD}=3.94) \quad(p=.04, d=0.30)$, a small effect. The Australian sample $(\mathrm{M}=9.39$, 
Table 3. First Animal Responses of Five-year-olds by Culture and Percentage of Respondents

\begin{tabular}{|c|c|c|c|c|c|c|}
\hline Australia & $\%$ & Taiwan & & $\%$ & US & $\%$ \\
\hline elephant & $16 \%$ & 長頸鹿 & giraffe & $24 \%$ & lion & $14 \%$ \\
\hline tiger & $15 \%$ & 大象 & elephant & $17 \%$ & tiger & $10 \%$ \\
\hline giraffe & $13 \%$ & 獅子 & lion & $17 \%$ & zebra & $10 \%$ \\
\hline cow & $9 \%$ & 兔子 & rabbit & $8 \%$ & bear & $9 \%$ \\
\hline lion & $9 \%$ & 馬 & horse & $4 \%$ & giraffe & $9 \%$ \\
\hline zebra & $9 \%$ & 老虎 & tiger & $4 \%$ & elephant & $7 \%$ \\
\hline dog & $3 \%$ & 斑馬 & zebra & $4 \%$ & horse & $7 \%$ \\
\hline horse & $3 \%$ & 猴子 & monkey & $3 \%$ & dog & $6 \%$ \\
\hline pig & $3 \%$ & 熊 & bear & $1 \%$ & cheetah & $2 \%$ \\
\hline alligator & $1 \%$ & 恐龍 & dinosaur & $1 \%$ & deer & $2 \%$ \\
\hline anteater & $1 \%$ & 小鳥 & bird & $<1 \%$ & monkey & $2 \%$ \\
\hline bear & $1 \%$ & 駱駝 & camel & $<1 \%$ & pig & $2 \%$ \\
\hline cat & $1 \%$ & 貓咪 & cat & $<1 \%$ & squirrel & $2 \%$ \\
\hline chicken & $1 \%$ & 牛 & cow & $<1 \%$ & cow & $1 \%$ \\
\hline dolphin & $1 \%$ & 鯂魚 & crocodile & $<1 \%$ & crocodile & $1 \%$ \\
\hline dragon & $1 \%$ & 狗 & dog & $<1 \%$ & dinosaur & $1 \%$ \\
\hline duck & $1 \%$ & 魚 & fish & $<1 \%$ & fox & $1 \%$ \\
\hline kangaroo & $1 \%$ & 梅花鹿 & formosan sika deer & $<1 \%$ & hippopotamus & $1 \%$ \\
\hline kiwi & $1 \%$ & 青蛙 & frog & $<1 \%$ & kitten & $1 \%$ \\
\hline snake & $1 \%$ & 河馬 & hippopotamus & $<1 \%$ & leopard & $1 \%$ \\
\hline Tasmanian devil & $1 \%$ & 無尾熊 & koala & $<1 \%$ & mountain lion & $1 \%$ \\
\hline \multirow[t]{13}{*}{ turtle } & $1 \%$ & 小綿羊 & lamb & $<1 \%$ & panda & $1 \%$ \\
\hline & & 蚚蜴 & lizard & $<1 \%$ & rabbit & $1 \%$ \\
\hline & & 長毛象 & mammoth & $<1 \%$ & rattle snake & $1 \%$ \\
\hline & & 麇鹿 & moose & $<1 \%$ & reindeer & $1 \%$ \\
\hline & & 老鼠 & mouse & $<1 \%$ & snake & $1 \%$ \\
\hline & & 貓熊 & panda & $<1 \%$ & toucan & $1 \%$ \\
\hline & & 企鵝 & penguin & $<1 \%$ & unicorn & $1 \%$ \\
\hline & & 豬 & pig & $<1 \%$ & & \\
\hline & & 北極熊 & polar bear & $<1 \%$ & & \\
\hline & & 螳螂 & praying mantis & $<1 \%$ & & \\
\hline & & 犀牛 & rhinoceros & $<1 \%$ & & \\
\hline & & 羊 & sheep & $<1 \%$ & & \\
\hline & & 烏龜 & turtle & $<1 \%$ & & \\
\hline
\end{tabular}


Table 4. First Animal Responses of Seven-year-olds by Culture and Percentage of Respondents

\begin{tabular}{|c|c|c|c|c|c|c|}
\hline Australia & $\%$ & Taiwan & & $\%$ & US & $\%$ \\
\hline tiger & $11 \%$ & 獅子 & lion & $15 \%$ & dog & $19 \%$ \\
\hline dog & $9 \%$ & 兔子 & rabbit & $13 \%$ & lion & $10 \%$ \\
\hline horse & $8 \%$ & 長頸鹿 & giraffe & $12 \%$ & zebra & $8 \%$ \\
\hline giraffe & $6 \%$ & 大象 & elephant & $11 \%$ & cat & $7 \%$ \\
\hline lion & $6 \%$ & 猴子 & monkey & $8 \%$ & cheetah & $6 \%$ \\
\hline bird & $5 \%$ & 牛 & cow & $5 \%$ & deer & $6 \%$ \\
\hline cat & $5 \%$ & 貓/貓咪 & cat & $4 \%$ & tiger & $6 \%$ \\
\hline cheetah & $5 \%$ & 老鼠 & mouse & $3 \%$ & giraffe & $5 \%$ \\
\hline pig & $5 \%$ & 老虎 & tiger & $3 \%$ & monkey & $5 \%$ \\
\hline zebra & $5 \%$ & 斑馬 & zebra & $2 \%$ & elephant & $4 \%$ \\
\hline cow & $3 \%$ & 無尾熊 & koala & $2 \%$ & horse & $4 \%$ \\
\hline crocodile & $3 \%$ & 熊 & bear & $1 \%$ & bird & $1 \%$ \\
\hline puppy & $3 \%$ & 狗 & dog & $1 \%$ & buck & $1 \%$ \\
\hline bat & $2 \%$ & 馬 & horse & $1 \%$ & bug & $1 \%$ \\
\hline bear & $2 \%$ & 企鵝 & penguin & $1 \%$ & cow & $1 \%$ \\
\hline bull & $2 \%$ & 蛇 & snake & $1 \%$ & coyote & $1 \%$ \\
\hline butterfly & $2 \%$ & 鳥/小鳥 & bird & $<1 \%$ & fish & $1 \%$ \\
\hline deer & $2 \%$ & 蝴蝶 & butterfly & $<1 \%$ & great white shark & $1 \%$ \\
\hline dolphin & $2 \%$ & 駱駝 & camel & $<1 \%$ & human & $1 \%$ \\
\hline duck & $2 \%$ & 馴鹿 & caribou & $<1 \%$ & kitten & $1 \%$ \\
\hline elephant & $2 \%$ & 獵豹 & cheetah & $<1 \%$ & owl & $1 \%$ \\
\hline hen & $2 \%$ & 雞 & chicken & $<1 \%$ & panda & $1 \%$ \\
\hline jaguar & $2 \%$ & 蟋蟀 & cricket & $<1 \%$ & penguin & $1 \%$ \\
\hline monkey & $2 \%$ & 鹿 & deer & $<1 \%$ & pig & $1 \%$ \\
\hline peacock & $2 \%$ & 恐龍 & dinosaur & $<1 \%$ & shark & $1 \%$ \\
\hline pronghorn & $2 \%$ & 龍 & dragon & $<1 \%$ & snake & $1 \%$ \\
\hline python & $2 \%$ & 老鷹 & eagle & $<1 \%$ & snow leopard & $1 \%$ \\
\hline sabre-tooth & $2 \%$ & 紅鶴 & flamingo & $<1 \%$ & tamarin & $1 \%$ \\
\hline seal & $2 \%$ & 山羊 & goat & $<1 \%$ & & \\
\hline \multirow[t]{5}{*}{ snake } & $2 \%$ & 河馬 & hippopotamus & $<1 \%$ & & \\
\hline & & 袋鼠 & kangaroo & $<1 \%$ & & \\
\hline & & 長毛象 & mammoth & $<1 \%$ & & \\
\hline & & 麇鹿 & moose & $<1 \%$ & & \\
\hline & & 貓熊 & panda & $<1 \%$ & & \\
\hline
\end{tabular}


Table 4. (Continued.)

\begin{tabular}{|c|c|c|c|c|c|c|}
\hline Australia & $\%$ & Taiwan & & $\%$ & US & $\%$ \\
\hline & & 孔雀 & peacock & $<1 \%$ & & \\
\hline & & 豬 & pig & $<1 \%$ & & \\
\hline & & 紅毛猩猩 & red hair ape & $<1 \%$ & & \\
\hline & & 犀牛 & rhinoceros & $<1 \%$ & & \\
\hline & & 羊 & sheep & $<1 \%$ & & \\
\hline & & 蜘蛛 & spider & $<1 \%$ & & \\
\hline & & 松鼠 & squirrel & $<1 \%$ & & \\
\hline & & 烏龜 & turtle & $<1 \%$ & & \\
\hline
\end{tabular}

Table 5. Animals Uniquely Named by Culture and Percentage of Respondents

\begin{tabular}{lllllll}
\hline Australia & $\%$ & Taiwan & & $\%$ & US & $\%$ \\
\hline emu & $4 \%$ & 乳牛 & dairy cow & $3 \%$ & hawk & $3 \%$ \\
\hline wombat & $4 \%$ & 麻雀 & sparrow & $3 \%$ & llama & $2 \%$ \\
\hline echidna & $3 \%$ & 梅花鹿 & formosan sika deer & $2 \%$ & buck & $2 \%$ \\
\hline kookaburra & $3 \%$ & 蟬 & cicada & $2 \%$ & catfish & $2 \%$ \\
\hline cockatoo & $3 \%$ & 飛鼠 & polatouche & $2 \%$ & coyote & $2 \%$ \\
\hline stink bug & $3 \%$ & 燕子 & swallow & $2 \%$ & gazelle & $2 \%$ \\
\hline killer whale & $2 \%$ & & & gerbil & mountain lion \\
\hline budgie & $2 \%$ & & & puma & $2 \%$ \\
\hline bull ant & $2 \%$ & & & & & \\
\hline fire ant & $2 \%$ & & & & \\
\hline iguana & $2 \%$ & & & & \\
\hline meerkat & $2 \%$ & & & & \\
\hline moth & $2 \%$ & & & & \\
\hline wasp & & & & & \\
\hline
\end{tabular}

Note. To be counted as unique, an animal had to be named by at least $2 \%$ of respondents in a given culture and $0 \%$ in both of the other cultures.

$\mathrm{SD}=3.67)$ differed from neither the US nor Taiwanese samples. There was no age $\times$ culture interaction $(\mathrm{F}(2,746)=2.39, p=.09)$.

The 10 most frequently named foods by culture appear in Table 6 . At both ages and in all three cultures, the top 10 is a diverse list that included fruits, vegetables, meat, and starches. The Taiwanese children included a number of superordinate category names (vegetable, meat, fish, and fruit) in the top 10 at five and seven years. The only other occurrence of a superordinate in the top 10 was meat in the Australian seven-yearolds' sample. At age five years, the overlap between cultures in the top 10 items was 


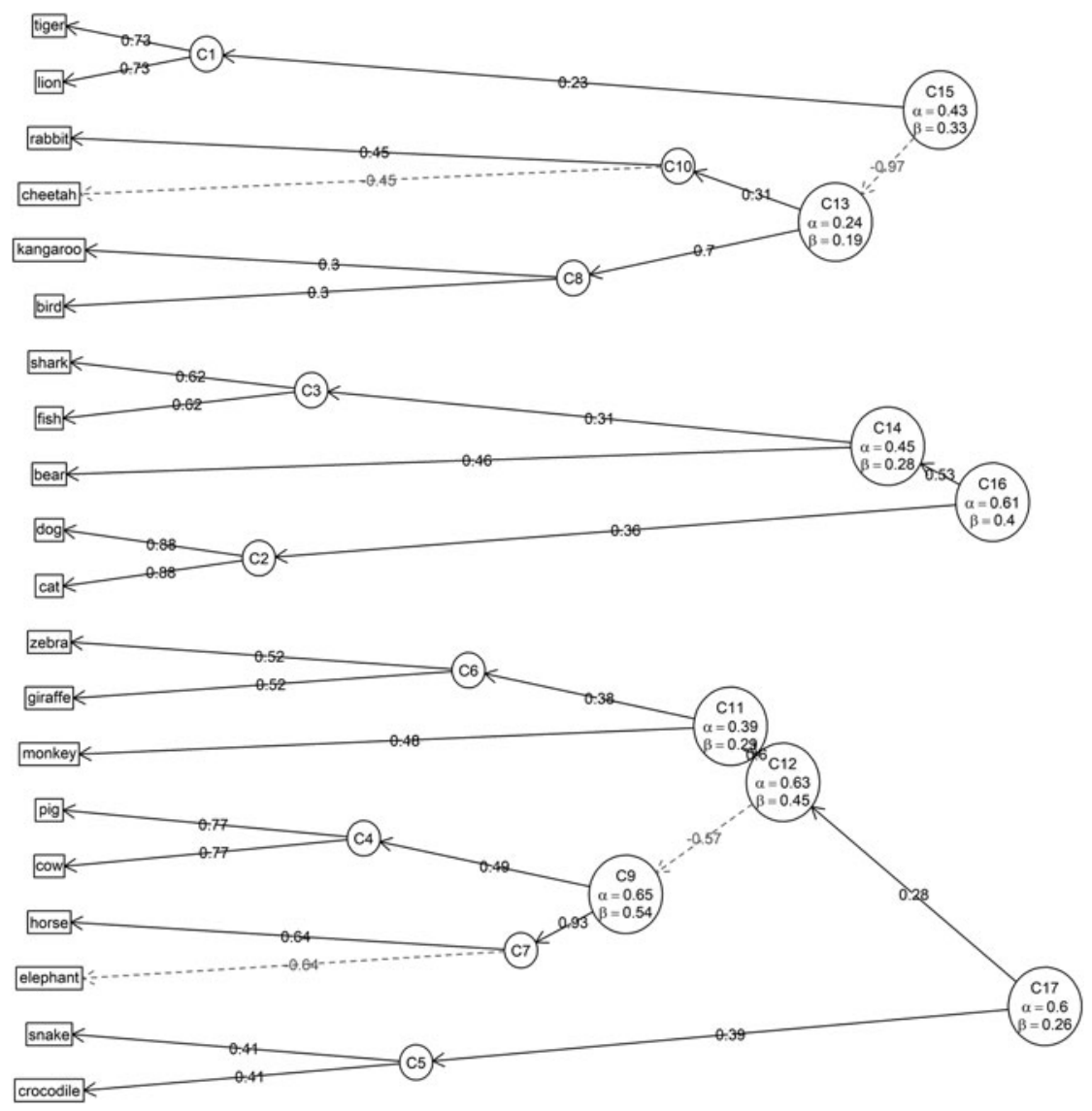

Figure 1. The structure of the Australian children's animal lexicon.

40\% for Australia and Taiwan, 45\% for Australia and the US, and 30\% for Taiwan and the US. At age seven years, the overlap between cultures in the top 10 items was $30 \%$ for Australia and Taiwan, 50\% for Australia and the US, and 20\% for Taiwan and the US. Apple was the only item that occurred in the top 10 of all three cultural groups (and at both ages).

Tables 7 and 8 list the children's first responses by culture. The list is highly variable. Apple was the most frequent first response common to all three cultures but, that said, it served as the first response for only $7-11 \%$ of participants in any given sample. For Taiwanese five-year-olds, [cooked]rice and vegetable were more common first responses than apple. At age seven, chocolate was more common than apple in the Australian sample, vegetable was more common than apple in the Taiwanese sample, and pizza was more common than apple in the US sample.

Table 9 specifies food items that were unique to a given culture. By comparing to Table 5, note that there were more unique foods than animals, and this was especially true in the Taiwanese sample. 

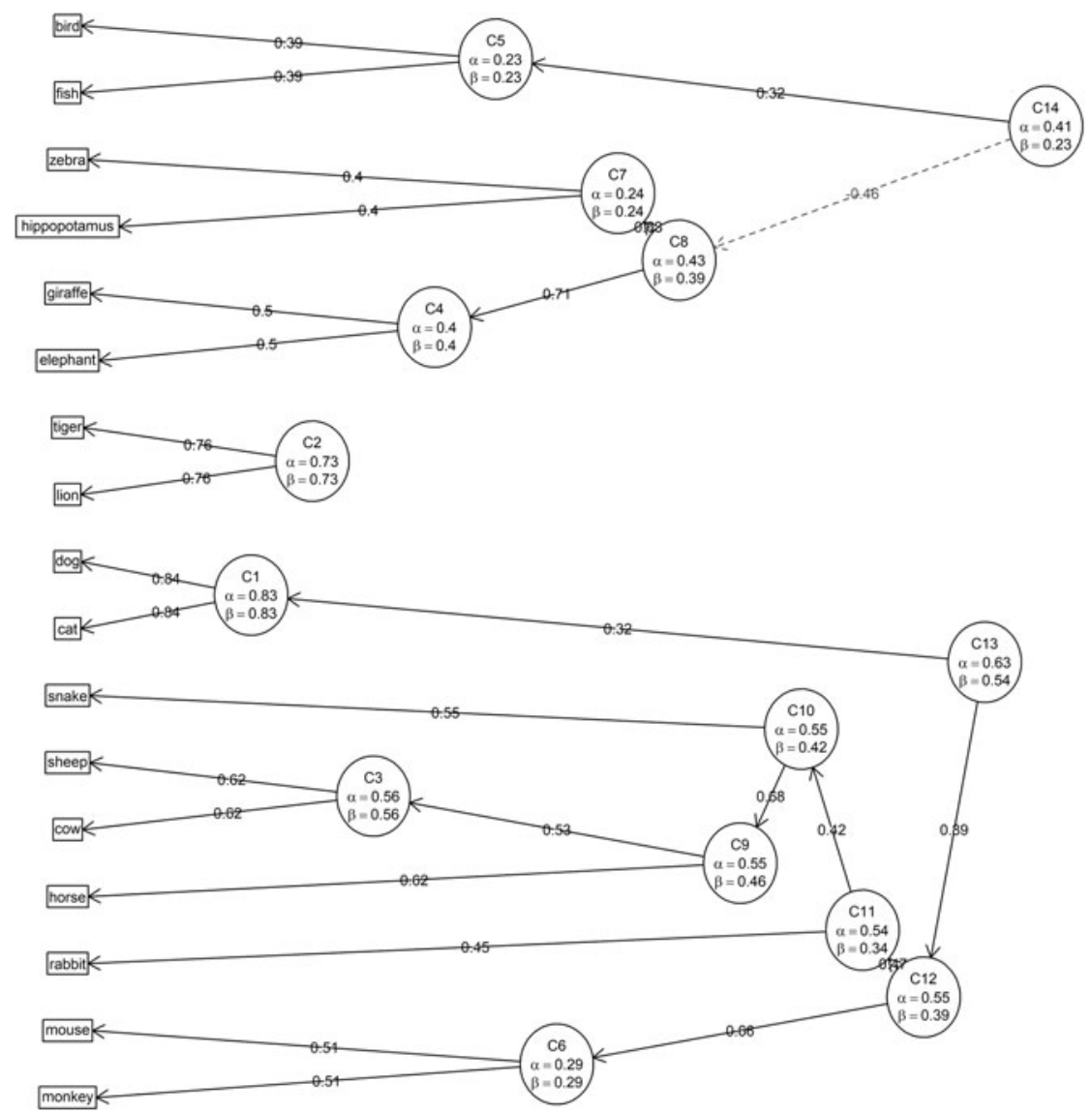

Figure 2. The structure of the Taiwanese children's animal lexicon.

The ICLUST results appear in Figures 4-6. There were 18 clusters in the Australian sample, 12 in the Taiwanese sample, and 13 in the US sample. Just as for animals, comparison of the three figures reveals a hierarchical organization of the food category in all three cultures. Some clusters were organized by taxon (e.g., fruit: watermelon-strawberry-grape-banana-apple in the Taiwanese sample), whereas others were organized by their frequent co-occurrence (e.g., bread-cheese in the Australian sample). The strongest relation was banana-apple in the Taiwanese and Australian samples and orange-apple in the US sample, perhaps because they are related by taxon (fruit) and also by co-occurrence (healthy snacks). A final commonality was that each cultural group demonstrated distinctions between items that are unrelated. For example, Taiwanese children considered noodles, cooked rice, and cookie to be neighbors (note that the word we translated as 'cookie' can also refer to any flour-based snack), but these neighbors were unrelated to carrot and cabbage. Australian children did not relate ice cream to pasta, whereas US children did not relate ice cream to the salad-bread cluster. 

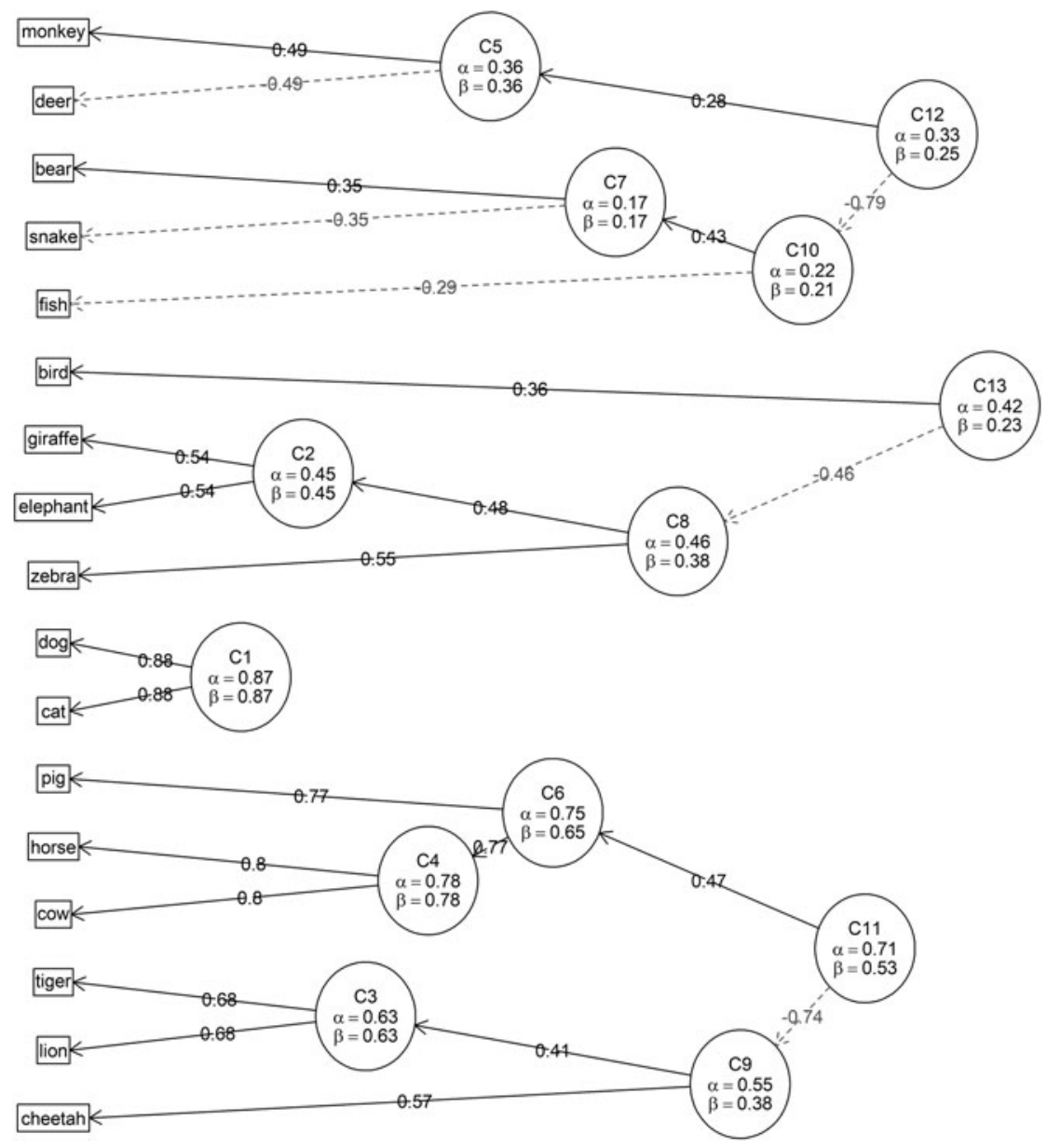

Figure 3. The structure of the US children's animal lexicon.

\section{Discussion}

Our purpose was to determine whether and how the content and structure of the developing semantic lexicon varies with cultural context. To accomplish this, we examined the animal and food names listed during a semantic fluency task by fiveand seven-year-olds from urban Australia, Taiwan, and the US.

Not surprisingly, in all three cultures, the seven-year-olds named more animals and foods than the five-year-olds. Linear increases in semantic fluency over childhood is a consistent finding across a diverse set of language communities (see John \& Rajashekhar, 2014, for a review). Another notable change with age was that the list of frequently named animals shifted from mammal names at age five to mammal names plus bird, fish, and reptile names at age seven. There was more overlap between the frequently named animal and food items in the Australian and US samples at age seven than five, but these were minimal changes that should be verified across a broader age-range. We will leave the question of whether cultural 
Table 6. Ten Most Frequent Food Responses of Five- and Seven-year-olds by Culture and Percentage of Respondents

\begin{tabular}{|c|c|c|c|c|c|c|}
\hline \multicolumn{2}{|l|}{ Australia } & \multicolumn{3}{|l|}{ Taiwan } & \multicolumn{2}{|l|}{ US } \\
\hline \multicolumn{7}{|c|}{ Five-year-olds } \\
\hline apple & $37 \%$ & 飯/飯飯 & [cooked] rice & $53 \%$ & apple & $31 \%$ \\
\hline banana & $30 \%$ & 菜/蔬菜 & vegetable & $45 \%$ & carrot & $27 \%$ \\
\hline pasta & $28 \%$ & 肉 & meat & $40 \%$ & chicken & $24 \%$ \\
\hline sandwich & $28 \%$ & 蘋果 & apple & $26 \%$ & grapes & $21 \%$ \\
\hline orange & $24 \%$ & 紅蘿葍/胡蘿葍 & carrot & $26 \%$ & pizza & $18 \%$ \\
\hline chicken & $21 \%$ & 高麗菜/白菜 & cabbage & $22 \%$ & salad & $17 \%$ \\
\hline pear & $19 \%$ & 青菜 & leafy vegetable & $21 \%$ & orange & $17 \%$ \\
\hline sausage & $18 \%$ & 香蕉 & banana & $20 \%$ & strawberry & $17 \%$ \\
\hline carrot & $16 \%$ & 西瓜 & watermelon & $17 \%$ & broccoli & $16 \%$ \\
\hline pizza & $16 \%$ & 葡萄 & grapes & $16 \%$ & corn & $15 \%$ \\
\hline \multirow[t]{3}{*}{ rice } & $16 \%$ & & & & hotdog & $15 \%$ \\
\hline & & & & & mac \& cheese & $15 \%$ \\
\hline & & & & & spaghetti & $15 \%$ \\
\hline \multicolumn{7}{|c|}{ Seven-year-olds } \\
\hline apple & $53 \%$ & 菜/蔬菜 & vegetable & $51 \%$ & pizza & $46 \%$ \\
\hline banana & $36 \%$ & 蘋果 & apple & $38 \%$ & apple & $42 \%$ \\
\hline chicken & $30 \%$ & 飯 & [cooked] rice & $37 \%$ & carrot & $33 \%$ \\
\hline chips & $30 \%$ & 肉 & meat & $36 \%$ & spaghetti & $33 \%$ \\
\hline tomato & $29 \%$ & 香蕉 & banana & $31 \%$ & hamburger & $31 \%$ \\
\hline pasta & $26 \%$ & 魚 & fish & $29 \%$ & orange & $31 \%$ \\
\hline carrot & $24 \%$ & 水果 & fruit & $28 \%$ & banana & $28 \%$ \\
\hline chocolate & $24 \%$ & 高麗菜/包心菜/白菜 & cabbage & $27 \%$ & chicken & $28 \%$ \\
\hline meat & $24 \%$ & 餅乾 & cookie & $27 \%$ & broccoli & $23 \%$ \\
\hline \multirow[t]{2}{*}{ orange } & $24 \%$ & 青菜 & leafy vegetable & $23 \%$ & grapes & $23 \%$ \\
\hline & & & & & hotdog & $23 \%$ \\
\hline
\end{tabular}

variations on the semantic lexicon grow or attenuate with age as an open question. Below we turn our attention to evidence of cultural influences on semantic fluency, content, and neighborhood structure in our sample as a whole.

\section{Fluency}

Differences between cultures in number of items named were minimal; the only exception being that the US children produced more food names than the Taiwanese 
Table 7. First Food Responses of Five-year-olds by Culture and Percentage of Respondents

\begin{tabular}{|c|c|c|c|c|c|c|}
\hline Australia & $\%$ & Taiwan & & $\%$ & US & $\%$ \\
\hline apple & $11 \%$ & 飯 & [cooked] rice & $14 \%$ & apple & $7 \%$ \\
\hline pasta & $8 \%$ & 蔬菜/菜 & vegetable & $13 \%$ & carrot & $7 \%$ \\
\hline rice & $8 \%$ & 蘋果 & apple & $8 \%$ & pizza & $7 \%$ \\
\hline banana & $6 \%$ & 青菜 & leafy vegetable & $7 \%$ & grape & $6 \%$ \\
\hline noodles & $6 \%$ & 肉/肉肉 & meat & $6 \%$ & chicken & $4 \%$ \\
\hline pizza & $6 \%$ & 水果 & fruit & $5 \%$ & salad & $4 \%$ \\
\hline chocolate & $5 \%$ & 餅乾 & cookie & $4 \%$ & broccoli & $3 \%$ \\
\hline bread & $3 \%$ & 花椰菜 & broccoli & $3 \%$ & $\begin{array}{l}\text { macaroni and } \\
\text { cheese }\end{array}$ & $3 \%$ \\
\hline broccoli & $3 \%$ & 高麗菜 & cabbage & $3 \%$ & spaghetti & $3 \%$ \\
\hline egg & $3 \%$ & 紅蘿蓄 & carrot & $3 \%$ & steak & $3 \%$ \\
\hline sandwich & $3 \%$ & 香蕉 & banana & $2 \%$ & watermelon & $3 \%$ \\
\hline sausage & $3 \%$ & 蛋 & egg & $2 \%$ & applesauce & $2 \%$ \\
\hline spaghetti & $3 \%$ & 西瓜 & watermelon & $2 \%$ & corn & $2 \%$ \\
\hline baked beans & $1 \%$ & 麵包 & bread & $1 \%$ & egg & $2 \%$ \\
\hline cake & $1 \%$ & 漢堡 & burger & $1 \%$ & fruit & $2 \%$ \\
\hline carrot & $1 \%$ & 巧克力 & chocolate & $1 \%$ & lemon & $2 \%$ \\
\hline cereal & $1 \%$ & 茄子 & eggplant & $1 \%$ & orange & $2 \%$ \\
\hline cheese & $1 \%$ & 葡萄 & grape & $1 \%$ & strawberry & $2 \%$ \\
\hline chicken & $1 \%$ & 麵 & noodles & $1 \%$ & tomato & $2 \%$ \\
\hline chips & $1 \%$ & 蘿葍 & radish & $1 \%$ & banana & $1 \%$ \\
\hline corn chips & $1 \%$ & 白飯/米飯 & $\begin{array}{l}\text { [cooked] plain } \\
\text { rice }\end{array}$ & $1 \%$ & bread & $1 \%$ \\
\hline fish & $1 \%$ & 稀飯 & rice porridge & $1 \%$ & cereal & $1 \%$ \\
\hline fish fingers & $1 \%$ & 香腸 & sausage & $1 \%$ & cheese & $1 \%$ \\
\hline ice cream & $1 \%$ & 蕃茄 & tomato & $1 \%$ & chicken nuggets & $1 \%$ \\
\hline lemon & $1 \%$ & 米 & [uncooked] rice & $1 \%$ & chips & $1 \%$ \\
\hline lolly (candy) & $1 \%$ & 苦瓜 & balsam pear & $<1 \%$ & corn dog & $1 \%$ \\
\hline mango & $1 \%$ & 竹简 & bamboo shoot & $<1 \%$ & edamame & $1 \%$ \\
\hline mashed potato & $1 \%$ & 糖果 & candy & $<1 \%$ & fish & $1 \%$ \\
\hline Nutri-grain & $1 \%$ & 包子 & Chinese bun & $<1 \%$ & French fries & $1 \%$ \\
\hline salad & $1 \%$ & 玉米 & corn & $<1 \%$ & fried egg & $1 \%$ \\
\hline schnitzel & $1 \%$ & 魚 & fish & $<1 \%$ & green beans & $1 \%$ \\
\hline $\begin{array}{l}\text { spaghetti } \\
\text { bolognaise }\end{array}$ & $1 \%$ & 法國麵包 & French bread & $<1 \%$ & hamburger & $1 \%$ \\
\hline
\end{tabular}


Table 7. (Continued.)

\begin{tabular}{|c|c|c|c|c|c|c|}
\hline Australia & $\%$ & Taiwan & & $\%$ & US & $\%$ \\
\hline strawberry & $1 \%$ & 薯條 & French fries & $<1 \%$ & hotdog & $1 \%$ \\
\hline toast & $1 \%$ & 芭樂 & guava & $<1 \%$ & ice cream & $1 \%$ \\
\hline \multirow[t]{15}{*}{ watermelon } & $1 \%$ & 棒棒糖 & lollipop & $<1 \%$ & macaroni & $1 \%$ \\
\hline & & 牛奶 & milk & $<1 \%$ & pasta & $1 \%$ \\
\hline & & 鳳梨 & pineapple & $<1 \%$ & $\begin{array}{l}\text { peanut butter and } \\
\text { jelly sandwich }\end{array}$ & $1 \%$ \\
\hline & & pizza & pizza & $<1 \%$ & peas & $1 \%$ \\
\hline & & 肉鬆 & pork floss & $<1 \%$ & pepper & $1 \%$ \\
\hline & & 馬鈴薯 & potato & $<1 \%$ & potato & $1 \%$ \\
\hline & & 拉麵 & ramen & $<1 \%$ & rice & $1 \%$ \\
\hline & & 沙拉 & salad & $<1 \%$ & rice noodles & $1 \%$ \\
\hline & & 草莓 & strawberry & $<1 \%$ & sandwich & $1 \%$ \\
\hline & & 壽司 & sushi & $<1 \%$ & soup & $1 \%$ \\
\hline & & 蛋餅 & $\begin{array}{c}\text { Taiwanese } \\
\text { omelet }\end{array}$ & $<1 \%$ & turkey sandwich & $1 \%$ \\
\hline & & 芋頭 & taro & $<1 \%$ & vegetable & $1 \%$ \\
\hline & & 豆腐 & tofu & $<1 \%$ & & \\
\hline & & 蔬果 & veggie-fruit & $<1 \%$ & & \\
\hline & & 空心菜 & water spinach & $<1 \%$ & & \\
\hline
\end{tabular}

children, a small effect. This difference could reflect a more varied diet among the US children, but that seems unlikely given that the Taiwanese children produced a longer list of culturally unique food names than the US children. Moreover, there was a non-significant trend for more animals named by the US children than the Taiwanese children, so a broader explanation may be needed. One possibility is that the US and Taiwanese children differed in executive function. Consider, for example, that when Russian and Romanian kindergarteners were asked to name animals and foods, the Russian children named fewer, a difference that the authors attribute to cultural influences on the development of executive control. Specifically, compared to Romanian teachers, Russian teachers place a higher value on emotional control, impulse control, persistence, and patience (Cheie, Veraksa, Zinchenko, Gorovaya, \& Visu-Petra, 2015). Although greater executive control is typically associated with enhanced fluency (e.g., Kavé et al., 2008; Koren et al., 2005; Raboutet et al., 2010), these authors hypothesize that the Russian children had learned a highly cautious style that privileged accuracy over speed, the result being fewer names generated during the minute-long interval. We used the semantic fluency task to tap the structure of the semantic lexicon, knowing full well that performance on this task also depends upon executive function. In future studies, it would be useful to administer an independent measure of executive control alongside the semantic fluency task to determine how much cultural (and age) variation is accounted for by the executive function performance. 
Table 8. First Food Responses of Seven-year-olds by Culture and Percentage of Respondents

\begin{tabular}{|c|c|c|c|c|c|c|}
\hline Australia & $\%$ & Taiwan & & $\%$ & US & $\%$ \\
\hline chocolate & $11 \%$ & 蔬菜/菜 & vegetable & $13 \%$ & pizza & $13 \%$ \\
\hline apple & $8 \%$ & 蘋果 & apple & $9 \%$ & apple & $7 \%$ \\
\hline spaghetti & $8 \%$ & 水果 & fruit & $8 \%$ & spaghetti & $7 \%$ \\
\hline vegetable & $6 \%$ & 肉/肉類 & meat & $7 \%$ & hamburger & $6 \%$ \\
\hline cake & $5 \%$ & 飯 & [cooked] rice & $5 \%$ & chicken & $5 \%$ \\
\hline $\begin{array}{l}\text { chips (French } \\
\text { fries) }\end{array}$ & $5 \%$ & 青菜 & leafy vegetable & $5 \%$ & $\begin{array}{l}\text { macaroni and } \\
\text { cheese }\end{array}$ & $5 \%$ \\
\hline curry & $5 \%$ & 餅乾 & cookie & $4 \%$ & carrot & $4 \%$ \\
\hline ice cream & $5 \%$ & 香蕉 & banana & $3 \%$ & macaroni & $4 \%$ \\
\hline orange & $5 \%$ & 蛋糕 & cake & $3 \%$ & watermelon & $4 \%$ \\
\hline pasta & $5 \%$ & 紅蘿䓒 & carrot & $3 \%$ & broccoli & $2 \%$ \\
\hline banana & $3 \%$ & 魚 & fish & $3 \%$ & corn & $2 \%$ \\
\hline carrot & $3 \%$ & 草莓 & strawberry & $3 \%$ & Goldfish & $2 \%$ \\
\hline egg & $3 \%$ & 麵包 & bread & $2 \%$ & hotdog & $2 \%$ \\
\hline noodles & $3 \%$ & 漢堡 & burger & $2 \%$ & popcorn & $2 \%$ \\
\hline pizza & $3 \%$ & 糖果 & candy & $2 \%$ & strawberry & $2 \%$ \\
\hline sausage & $3 \%$ & 雞腿 & drumstick & $2 \%$ & taco & $2 \%$ \\
\hline candy & $2 \%$ & 薯條 & French fries & $2 \%$ & cake & $1 \%$ \\
\hline chicken & $2 \%$ & 冰淇淋 & ice cream & $2 \%$ & cheese & $1 \%$ \\
\hline Chinese food & $2 \%$ & 蕃茄 & tomato & $2 \%$ & $\begin{array}{l}\text { chicken on the } \\
\text { bone }\end{array}$ & $1 \%$ \\
\hline flour & $2 \%$ & 花椰菜 & broccoli & $1 \%$ & chili & $1 \%$ \\
\hline kupus & $2 \%$ & 高麗菜 & cabbage & $1 \%$ & chocolate & $1 \%$ \\
\hline lamb & $2 \%$ & 雞肉 & chicken & $1 \%$ & cookie & $1 \%$ \\
\hline lasagna & $2 \%$ & 洋芋片 & chips & $1 \%$ & enchilada & $1 \%$ \\
\hline $\begin{array}{l}\text { macaroni and } \\
\text { cheese }\end{array}$ & $2 \%$ & 青椒 & green pepper & $1 \%$ & French fries & $1 \%$ \\
\hline olive & $2 \%$ & 麵 & noodles & $1 \%$ & frosting & $1 \%$ \\
\hline potato & $2 \%$ & pizza & pizza & $1 \%$ & fruit & $1 \%$ \\
\hline rice & $2 \%$ & 馬鈴薯 & potato & $1 \%$ & grape & $1 \%$ \\
\hline sandwich & $2 \%$ & 三明治 & sandwich & $1 \%$ & Hershey kiss & $1 \%$ \\
\hline \multirow[t]{4}{*}{ tomato } & $2 \%$ & 牛排 & steak & $1 \%$ & ice cream & $1 \%$ \\
\hline & & 西瓜 & watermelon & $1 \%$ & lettuce & $1 \%$ \\
\hline & & 牛肉 & beef & $<1 \%$ & mango & $1 \%$ \\
\hline & & 飲料 & beverage & $<1 \%$ & noodles & $1 \%$ \\
\hline
\end{tabular}


Table 8. (Continued.)

\begin{tabular}{|c|c|c|c|c|c|c|}
\hline \multirow[t]{2}{*}{ Australia } & \multirow[t]{2}{*}{$\%$} & \multicolumn{2}{|l|}{ Taiwan } & \multirow{2}{*}{$\begin{array}{c}\% \\
<1 \%\end{array}$} & \multirow{2}{*}{$\frac{\text { US }}{\text { onion }}$} & \multirow{2}{*}{$\begin{array}{c}\% \\
1 \%\end{array}$} \\
\hline & & 泈肉飯 & braised pork rice & & & \\
\hline & & 芹菜 & celery & $<1 \%$ & pear & $1 \%$ \\
\hline & & cheese & cheese & $<1 \%$ & pepperoni pizza & $1 \%$ \\
\hline & & 巧克力 & chocolate & $<1 \%$ & pop tart & $1 \%$ \\
\hline & & 可樂 & cola & $<1 \%$ & salmon & $1 \%$ \\
\hline & & 玉米 & corn & $<1 \%$ & sausage & $1 \%$ \\
\hline & & 玉米濃湯 & corn soup & $<1 \%$ & stuffed shells & $1 \%$ \\
\hline & & 棉花糖 & cotton candy & $<1 \%$ & tomato & $1 \%$ \\
\hline & & 咖哩飯 & curried rice & $<1 \%$ & & \\
\hline & & 香菇 & dried mushroom & $<1 \%$ & & \\
\hline & & 茄子 & eggplant & $<1 \%$ & & \\
\hline & & 羊 & goat & $<1 \%$ & & \\
\hline & & 葡萄 & grape & $<1 \%$ & & \\
\hline & & 熱狗 & hotdog & $<1 \%$ & & \\
\hline & & 牛奶 & milk & $<1 \%$ & & \\
\hline & & 大白菜 & nappa cabbage & $<1 \%$ & & \\
\hline & & 豬肉 & pork & $<1 \%$ & & \\
\hline & & 布丁 & pudding & $<1 \%$ & & \\
\hline & & 蘿葍 & radish & $<1 \%$ & & \\
\hline & & 稀飯 & rice porridge & $<1 \%$ & & \\
\hline & & 香腸 & sausage & $<1 \%$ & & \\
\hline & & 義大利麵 & spaghetti & $<1 \%$ & & \\
\hline & & 蕃薯 & sweet potato & $<1 \%$ & & \\
\hline & & 橘子 & tangerine & $<1 \%$ & & \\
\hline & & 土司 & toast & $<1 \%$ & & \\
\hline & & 蕃茄炒蛋 & $\begin{array}{l}\text { tomato with } \\
\text { scrambled egg }\end{array}$ & $<1 \%$ & & \\
\hline & & 火雞 & turkey & $<1 \%$ & & \\
\hline & & 米 & [uncooked] rice & $<1 \%$ & & \\
\hline & & 水 & water & $<1 \%$ & & \\
\hline
\end{tabular}

\section{Content}

Because young children, especially those in cities, tend to learn about animals from media, but food from direct experience, we predicted more cultural similarity in animal naming than food naming. This prediction held as measured by overlap in 
Table 9. Foods Uniquely Named by Culture and Percentage of Respondents

\begin{tabular}{|c|c|c|c|c|c|c|}
\hline Australia & $\%$ & Taiwan & & $\%$ & US & $\%$ \\
\hline mandarin & $8 \%$ & 青菜 & leafy vegetable & $23 \%$ & corndog & $5 \%$ \\
\hline $\begin{array}{l}\text { spaghetti } \\
\text { bolognaise }\end{array}$ & $6 \%$ & 橘子 & tangerine & $10 \%$ & $\begin{array}{l}\text { peanut butter and } \\
\text { jelly sandwich }\end{array}$ & $4 \%$ \\
\hline ice block & $4 \%$ & 芭樂 & guava & $9 \%$ & pickle & $4 \%$ \\
\hline baked beans & $3 \%$ & 雞腿 & drumstick & $6 \%$ & apple sauce & $3 \%$ \\
\hline sausage roll & $3 \%$ & 香菇 & dried mushroom & $5 \%$ & burrito & $3 \%$ \\
\hline Vegemite & $3 \%$ & 炸雞 & fried chicken & $4 \%$ & Goldfish & $3 \%$ \\
\hline Chinese food & $2 \%$ & 茄子 & eggplant & $4 \%$ & $M-n-M$ & $3 \%$ \\
\hline fish and chips & $2 \%$ & 白蘿萄 & Japanese radish & $4 \%$ & blackberry & $2 \%$ \\
\hline meat pie & $2 \%$ & 稀飯 & rice porridge & $3 \%$ & cheese sandwich & $2 \%$ \\
\hline Nutella & $2 \%$ & 雞排 & chicken steak & $3 \%$ & chocolate milk & $2 \%$ \\
\hline Nutri-grain & $2 \%$ & 火鍋 & hot pot & $3 \%$ & enchilada & $2 \%$ \\
\hline roast beef & $2 \%$ & 蓮霧 & java apple & $3 \%$ & fruit snack & $2 \%$ \\
\hline tea & $2 \%$ & 大白菜 & napa cabbage & $3 \%$ & granola bar & $2 \%$ \\
\hline tuna & $2 \%$ & 米 & uncooked rice & $3 \%$ & grilled cheese & $2 \%$ \\
\hline \multirow[t]{16}{*}{ Weet-bix } & $2 \%$ & 空心菜 & water spinach & $2 \%$ & Pop tart & $2 \%$ \\
\hline & & 小白菜 & $\begin{array}{c}\text { baby napa } \\
\text { cabbage }\end{array}$ & $2 \%$ & pretzel & $2 \%$ \\
\hline & & 苦瓜 & balsam pear & $2 \%$ & pumpkin pie & $2 \%$ \\
\hline & & 牛肉麵 & beef noodles & $2 \%$ & quesadilla & $2 \%$ \\
\hline & & 水餃 & boiled dumpling & $2 \%$ & ranch dressing & $2 \%$ \\
\hline & & 包子 & Chinese bun & $2 \%$ & Tootsie roll & $2 \%$ \\
\hline & & 白菜 & Chinese cabbage & $2 \%$ & & \\
\hline & & 咖哩飯 & curried rice & $2 \%$ & & \\
\hline & & 魚排 & fillet & $2 \%$ & & \\
\hline & & 炒麵 & fried noodles & $2 \%$ & & \\
\hline & & 貢丸 & $\begin{array}{l}\text { Hsinchu-style } \\
\text { meat ball }\end{array}$ & $2 \%$ & & \\
\hline & & 柚子 & persimmon & $2 \%$ & & \\
\hline & & 布丁 & pudding & $2 \%$ & & \\
\hline & & 饅頭 & steamed bun & $2 \%$ & & \\
\hline & & 湯圓 & $\begin{array}{l}\text { sticky rice } \\
\text { dumpling }\end{array}$ & $2 \%$ & & \\
\hline & & 壽司 & sushi & $2 \%$ & & \\
\hline
\end{tabular}

Note. To be counted as unique, a food had to be named by at least $2 \%$ of respondents in a given culture and $0 \%$ in both of the other cultures. 


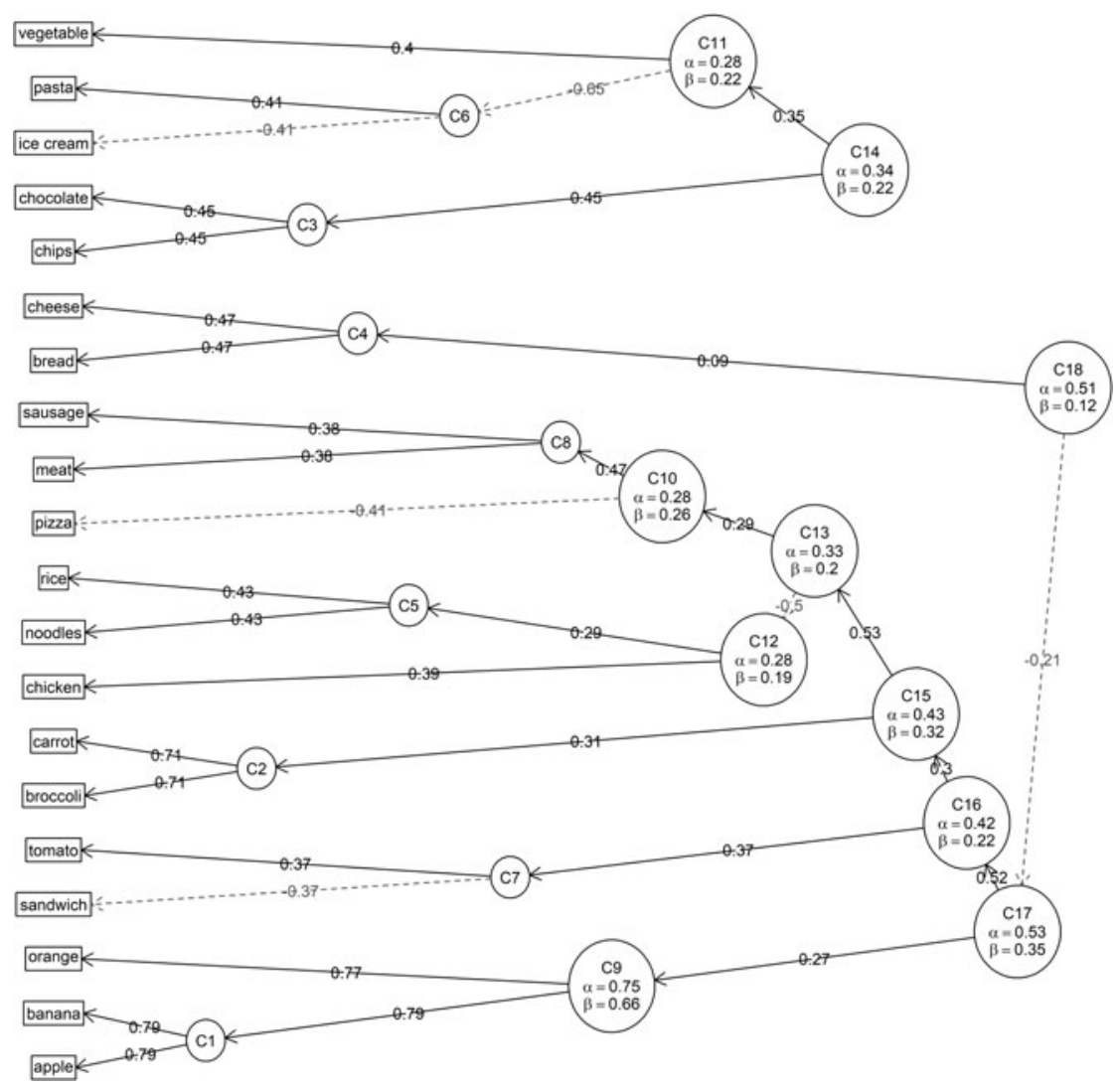

Figure 4. The structure of the Australian children's food lexicon.

frequent names, prototypicality, unique names, and clustering. The overlap between the ten most frequent animal names was high, ranging from $70 \%$ to $90 \%$, depending on the ages and samples in question; whereas the overlap between the ten most frequent food names was modest, ranging from $20 \%$ to $50 \%$. The prototypical animal was mammal. Mammals comprised over $80 \%$ of first responses in all cultures and all ages, a finding akin to that reported for three North American cultures in Winkler-Rhoades et al. (2010) and three South American cultures in Taverna et al. (2014). There was no clearly prototypical food common to the three cultures. The list of unique food names was longer than the list of unique animal names, again revealing less cultural variation in knowledge of animal names. Finally, the only commonality in the food clusters was that children in all three cultures clustered apple and banana. In contrast, four animal clusters were common to the three cultures: cat-dog, horse-cow, tiger-lion, and zebra-giraffe.

With clear evidence of greater cultural variation in food naming than animal naming, we move on to explore the nuances revealed by triangulating cultural distinctions defined by heritage (East-West) and population density (metropolitanurban). Within the food category, we predicted variation by heritage; within the animal category, we predicted variation by population density. 

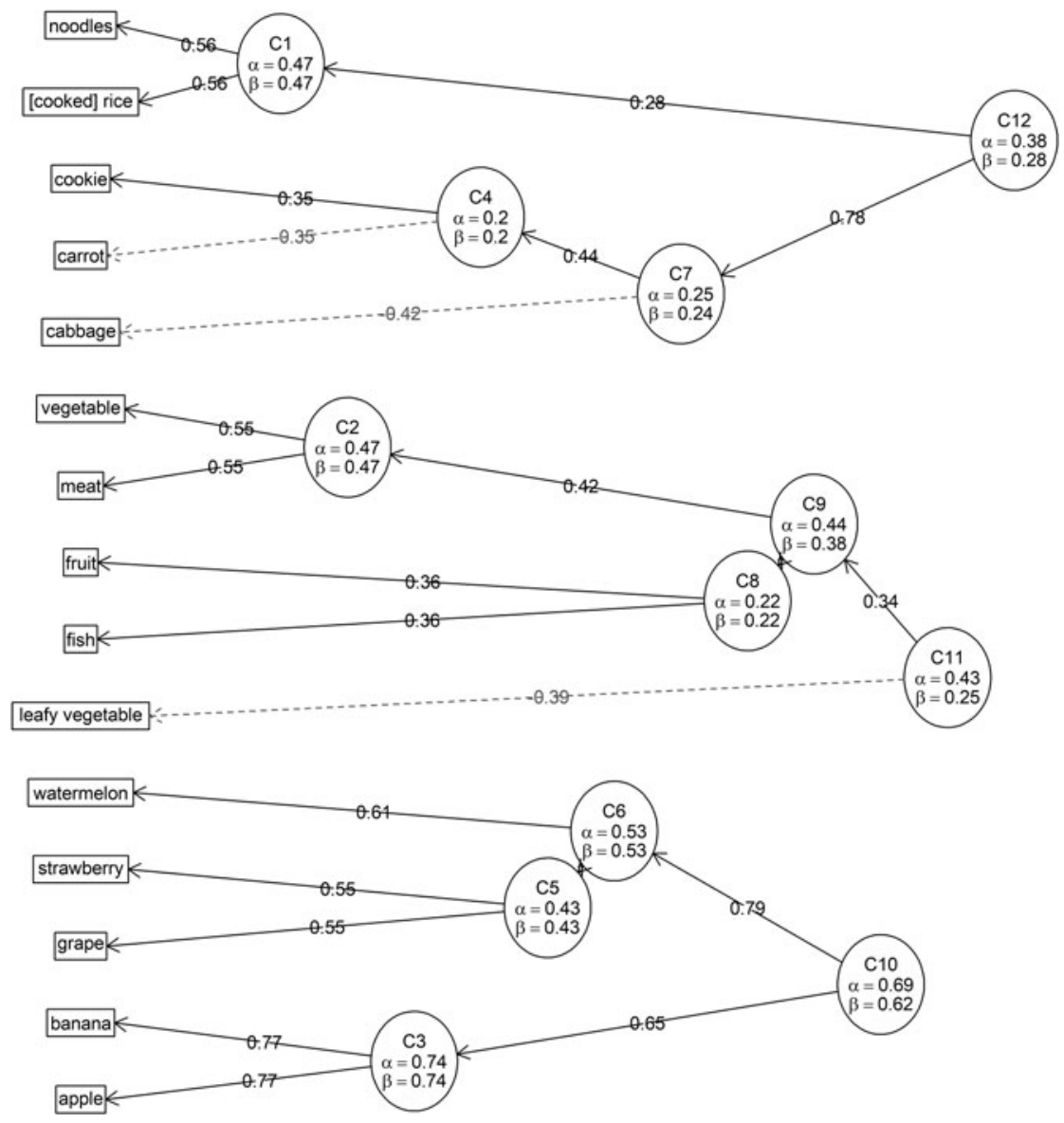

Figure 5. The structure of the Taiwanese children's food lexicon.

\section{Food names}

The predicted variation by heritage was based on the logic that the children in the Taiwanese sample would likely have Eastern diets and therefore different direct experiences with food than the children in the Australian and US samples, who would likely have Western diets. Patterns in frequent and unique names supported this prediction. The highest amount of overlap in frequent food names, 50\%, occurred in the Australian and US seven-year-olds; whereas the lowest overlap, 20\%, occurred in the US and Taiwanese seven-year-olds. Moreover, many of the unique foods in the Taiwanese sample were dishes traditional to the culture (e.g., hot pot, Chinese bun, sticky rice dumpling), but in contrast, the unique foods in the Australian and US samples included a number of processed foods common to Western diets (e.g., Vegemite and Weet-Bix for Australia; Pop Tarts and Tootsie Rolls for the US). These patterns underscore the importance of culturally specific, direct experiences on food name learning. 


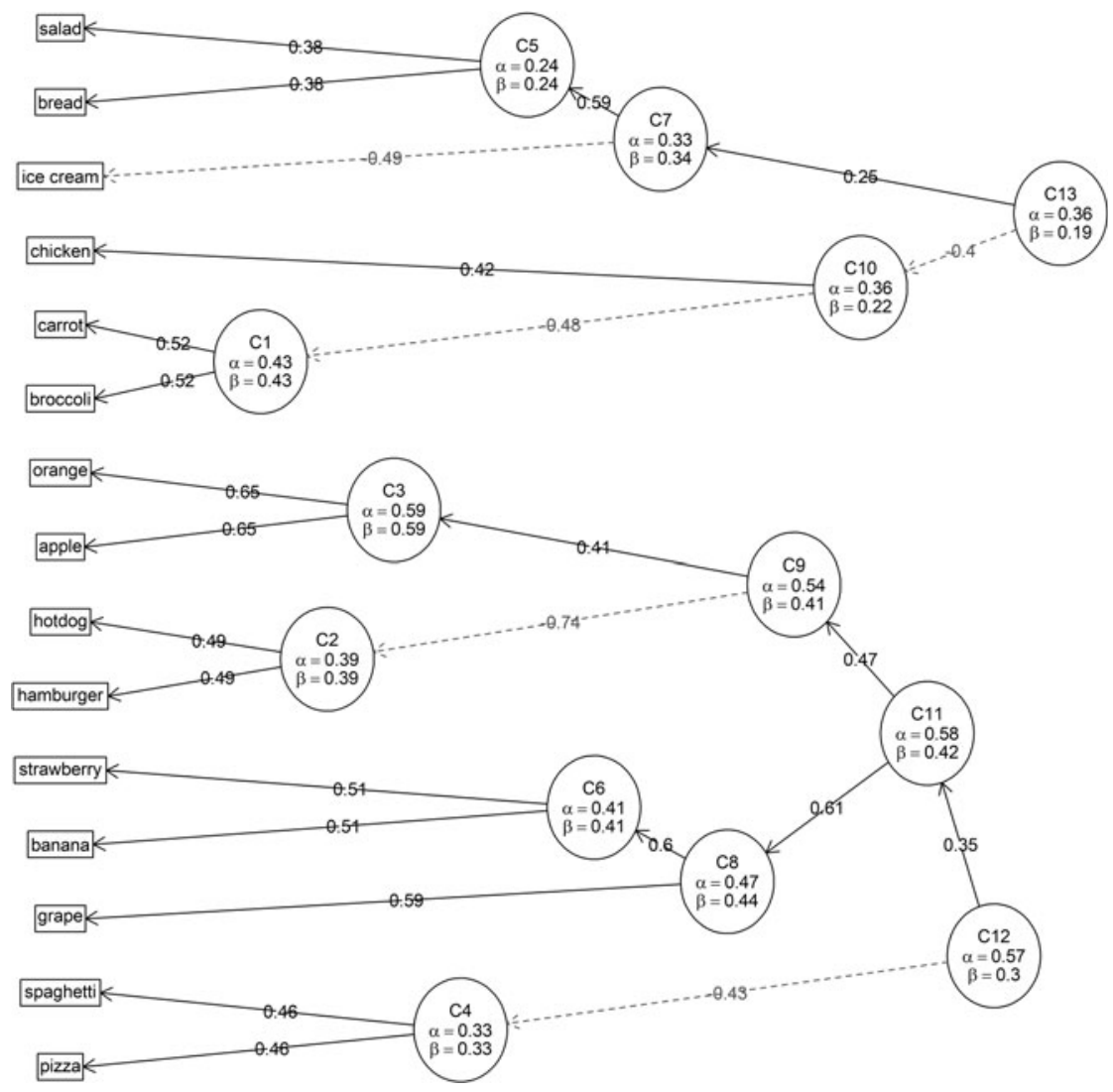

Figure 6. The structure of the US children's food lexicon.

\section{Animal names}

Counter to prediction, we found no evidence that animal naming varied with population density. Although surrounded by farmland, the US children rarely named farm animals. This finding suggests that limited direct experience with animals is not exclusively characteristic of residents of metropolitan areas. The US children, like the Australian and Taiwanese children, instead named many wild animals. Like Winkler-Rhoades et al. (2010), we attribute this finding to the popularity of wild animals in children's media, not only books (Freebody \& Baker, 1985; Marriot, 2002) but also films. Many Disney films come to mind: Dumbo, The Jungle Book, The Lion King, and Zootopia. This explanation gains credence from Taverna et al. (2014), who found that native Amerindian children with limited exposure to media rarely listed exotic wild animals when asked to name living things.

Books and films open worlds that are unavailable to children in everyday life. As such, they are rich sources for learning words. Are there drawbacks? There is the potential for the fantasy worlds in books and films to mislead. Books for preschoolers that include life science content frequently include misconceptions and anthropomorphic portrayals of animals (Sackes, Trundle, \& Flevares, 2009) and, when books and films replace genuine experiences in nature, anthropocentric 
thinking can result (Ross et al., 2003). This finding holds implications for selecting, talking about, and teaching from children's media.

The most striking example of variation in animal naming had nothing to do with population density; rather, it was a reflection of Eastern cultural practices. Specifically, the children in the Taiwanese sample, and only those children, named and clustered animals according to the Chinese zodiac. Although we did not anticipate this specific outcome, it is interpretable in hindsight. In East Asian countries, birth rates (Grech, 2015) and investments in children's educational outcomes (Tan, Wang, \& Zhang, 2018) vary in predictable ways with the signs thought to be lucky or unlucky, suggesting that traditional beliefs about the zodiac remain highly influential there.

\section{Neighborhood structure}

Because of the scaffolding of hierarchical relations provided by the structure of Mandarin, we predicted linguistic variation in the food and animal neighborhood structures. Specifically, we predicted more superordinate naming and more sophisticated hierarchical structures in the responses of the Mandarin-speaking Taiwanese children than the English-speaking Australian or US children. We found only partial support for this prediction.

Mandarin speakers named more foods at the superordinate level than the English speakers did. In Mandarin, food names, like other names, include many compounds that share a head (e.g., jilrou4 'chicken-meat', zhulrou4 'pig-meat', niu2rou4 'cow-meat'). With rare exceptions (e.g., catfish, breadfruit), English words for food do not follow this pattern. It is tempting to conclude that the frequency of compounds in Mandarin scaffold the children's knowledge of superordinate names but, curiously, we did not find the same pattern in Mandarin animal naming. A useful next step would be to determine whether the frequency of compounding varies by category in Mandarin; that is, perhaps the strength of the scaffold is greater for food names than animal names in Mandarin. An alternative possibility is that, in Mandarin, compound words for foods tend to highlight a higher level in the taxonomic hierarchy than compound words for animals. Consider the example presented in the 'Introduction' of this paper: whereas English has bison, buffalo, cow, ox, yak, dairy cattle, bull, and calf, all of these words for bovines in Mandarin end with niu2 'cow'. Unlike the superordinate term meat in chicken-meat, cow is a basic-level term. Most children, and adults, tend to name at the basic level (Rosch, Mervis, Gray, Johnson, \& Boyes-Braem, 1976). Hence, structures that highlight basic-level relationships would not serve to differentiate Mandarin from English speakers.

We also predicted that the Mandarin-speaking Taiwanese children would produce more and larger clusters than the English-speaking Australian and US children. This was not the case. Although the Taiwanese children presented the largest (nine-item) cluster in the animal data, there was a similarly sized eight-item cluster in the Australian food data. Moreover, the Australian sample included the most clusters, 17 for animals and 18 for foods. In other words, we found no evidence that Mandarin compounds serve as a bootstrap that enables a more sophisticated structuring of the semantic lexicon among young Mandarin learners than among their English-speaking peers. Recall that Lin et al. (1990) found that Mandarin-speaking Taiwanese children demonstrate adult-like taxonomic clusters earlier than children from the US. However, their task involved a typicality judgment, not naming, and the children they sampled ranged from five to twelve years of age, not five to seven. Therefore, we may have 
missed the precocious clustering thought characteristic of Mandarin-speaking children because we sampled with the wrong task or at the wrong ages.

Overall, the neighborhood structures were more notable for their similarity than their differences across languages. For both food and animals, children in all three samples exhibited hierarchically organized clusters. The clusters themselves were cross-categorized, some were organized by taxon (e.g., vegetables, felines), some by co-occurrence (e.g., snacks, pets), and others by both (e.g., meats to consume at a cookout). Four- to seven-year-olds studied by Nguyen and Murphy (2003) also demonstrated multiple bases for categorizing, as did the five- to fourteen-year-olds in Taverna et al. (2014). Clearly, children are flexible in their appreciation of lexicalsemantic relationships. Of course clustering like-kinds logically implies the separation of disparate kinds. This separate organization was also evident across cultures in the negative correlations between items such as rabbit-cheetah. Just as learning the link between a word and its referent entails pruning away links between that word and non-referents (McMurray, Horst, \& Samuelson, 2012), knowledge of semantic relationships entails the awareness that some words are not related.

\section{Conclusions}

Patterns in the animal and food naming of five- to seven-year-old children from three communities distinguished by language (English-Mandarin), cultural heritage (West-East), and population density (Metropolitan-Urban) revealed similarly hierarchical, yet flexible, organization of the semantic lexicon. The content of the lexicon varied with cultural heritage, and this was particularly true of food names, where differences associated with Eastern and Western diets were apparent. In all three communities, mammals, especially wild mammals, were predominant during animal naming, a likely influence of children's media on animal name learning. The seven-year-olds, but not the five-year-olds, also frequently named birds, fish, and reptiles. The influence of the Chinese zodiac was evident in the clustering of animal names in the Taiwanese sample. There was no apparent influence of population density and little influence of language, except that the Taiwanese children more frequently named foods at the superordinate level, a possible influence of the morphological structure of Mandarin. Children learn words in response to the myriad of opportunities afforded to them by the language, artifacts, and practices of their culture as experienced first-hand or through media, and we can discern these cultural influences on the developing semantic lexicon.

\section{Supplementary materials}

For supplementary material for this paper, please visit <https://doi.org/10.1017/ S0305000918000211>.

Acknowledgments. We thank Nichole Eden and Timothy Arbisi-Kelm for assistance with data collection, Helin Hernandez for assistance with figures, and the CCDLL Lab Group for input on an earlier draft.

\section{References}

Beals, D. E. (1997). Sources of support for learning words in conversation: evidence from mealtimes. Journal of Child Language, 24(3), 673-94. 
Chami, S., Munro, N., Docking, K., McGregor, K., Arciuli, J., Baker, E., \& Heard, R. (2018). Changes in semantic fluency across childhood: normative data from Australian-English speakers. International Journal of Speech-Language Pathology, 20(2), 262-73.

Cheie, L., Veraksa, A., Zinchenko, Y., Gorovaya, A., \& Visu-Petra, L. (2015). A cross-cultural investigation of inhibitory control, generative fluency, and anxiety symptoms in Romanian and Russian preschoolers. Child Neuropsychology, 21(2), 121-49.

Chen, S. M. (2012). Lexical organization in Mandarin-speaking children: insights from the semantic fluency task (Master's thesis), The University of Iowa. Retrieved from <https://search.proquest.com/openview/

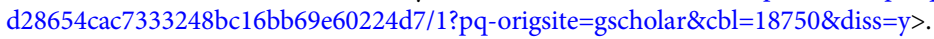

Chung, O. (2011). Mung beans and crocodiles: children's book publishing in Taiwan. Taiwan Today. Retrieved from <https://taiwantoday.tw/news.php?post $=13698$ \&unit $=8,8,29,32,32,45>$.

Crowe, S. J., \& Prescott, T. J. (2003). Continuity and change in the development of category structure: insights from the semantic fluency task. International Journal of Behavioral Development, 27(5), 467-79.

Fiese, B. H., Tomcho, T. J., Douglas, M., Josephs, K., Poltrock, S., \& Baker, T. (2002). A review of 50 years of research on naturally occurring family routines and rituals: Cause for celebration? Journal of Family Psychology, 16(4), 381-90.

Foy, J. G., \& Mann, V. (2003). Home literacy environment and phonological awareness in preschool children: differential effects for rhyme and phoneme awareness. Applied Psycholinguistics, 24(1), 59-88.

Freebody, P., \& Baker, C. (1985). Children's first schoolbooks: introductions to the culture of literacy. Harvard Educational Review, 55(4), 381-99.

Grech, V. (2015). The influence of the Chinese zodiac on the male-to-female ratio at birth in Hong Kong. Journal of the Chinese Medical Association, 78(5), 287-91.

Hart, B., \& Risley, T. R. (1995). Meaningful differences in the everyday experience of young American children. Baltimore, MD: Paul H. Brookes Publishing.

Hoff, E. (2006). How social contexts support and shape language development. Developmental Review, 26(1), 55-88.

Hoff, E., \& Naigles, L. (2002). How children use input to acquire a lexicon. Child Development, 73(2), 418-33.

Hurks, P. P., Schrans, D., Meijs, C., Wassenberg, R., Feron, F. J. M., \& Jolles, J. (2010). Developmental changes in semantic verbal fluency: analyses of word productivity as a function of time, clustering, and switching. Child Neuropsychology, 16(4), 366-87.

John, S., \& Rajashekhar, B. (2014). Word retrieval ability on semantic fluency task in typically developing Malayalam-speaking children. Child Neuropsychology, 20(2), 182-95.

Kail, R., \& Nippold, M. A. (1984). Unconstrained retrieval from semantic memory. Child Development, 55(3), 944-51.

Kavé, G., Kigel, S., \& Kochva, R. (2008). Switching and clustering in verbal fluency tasks throughout childhood. Journal of Clinical and Experimental Neuropsychology, 30(3), 349-59.

Koren, R., Kofman, O., \& Berger, A. (2005). Analysis of word clustering in verbal fluency of school-aged children. Archives of Clinical Neuropsychology, 20(8), 1087-104.

Lin, P. J., Schwanenflugel, P. J., \& Wisenbaker, J. M. (1990). Category typicality, cultural familiarity, and the development of category knowledge. Developmental Psychology, 26(5), 805-13.

Lucariello, J., Kyratzis, A., \& Nelson, K. (1992). Taxonomic knowledge: What kind and when? Child Development, 63(4), 978-98.

Lumeng, J. C., Zuckerman, M. D., Cardinal, T., \& Kaciroti, N. (2005). The association between flavor labeling and flavor recall ability in children. Chemical Senses, 30(7), 565-74.

Marriott, S. (2002). Red in tooth and claw? Images of nature in modern picture books. Children's Literature in Education, 33(3), 175-83.

Marshall, C. R., Rowley, K., Mason, K., Herman, R., \& Morgan, G. (2013). Lexical organization in deaf children who use British Sign Language: evidence from a semantic fluency task. Journal of Child Language, 40(1), 193-220.

McMurray, B., Horst, J. S., \& Samuelson, L. K. (2012). Word learning emerges from the interaction of online referent selection and slow associative learning. Psychological Review, 119(4), 831-77.

Mura Paroche, M., Caton, S. J., Vereijken, C. M., Weenen, H., \& Houston-Price, C. (2017). How infants and young children learn about food: a systematic review. Frontiers in Psychology, 8, 1046. 
Nash, H. M., \& Snowling, M. J. (2008). Semantic and phonological fluency in children with Down syndrome: Atypical organization of language or less efficient retrieval strategies? Cognitive Neuropsychology, 25(5), 690-703.

Nelson, K., \& Nelson, A. P. (1990). Category production in response to script and category cues by kindergarten and second-grade children. Journal of Applied Developmental Psychology, 11(4), 431-46.

Nguyen, S. P., \& Murphy, G. L. (2003). An apple is more than just a fruit: cross-classification in children's concepts. Child Development, 74(6), 1783-806.

Ojalehto, B. L., \& Medin, D. L. (2015). Perspectives on culture and concepts. Annual Review of Psychology, 66, 249-75.

Packard, J. L. (2000). The morphology of Chinese: a linguistic and cognitive approach. Cambridge University Press.

Pekkala, S., Goral, M., Hyun, J., Obler, L. K., Erkinjuntti, T., \& Albert, M. L. (2009). Semantic verbal fluency in two contrasting languages. Clinical Linguistics \& Phonetics, 23(6), 431-45.

Peña, E. D., Bedore, L. M., \& Zlatic-Giunta, R. (2002). Category-generation performance of bilingual children: the influence of condition, category, and language. Journal of Speech, Language, and Hearing Research, 45(5), 938-47.

R Core Team (2016). R: A language and environment for statistical computing. R Foundation for Statistical Computing, Vienna, Austria. Retrieved from <https://www.R-project.org/>.

Raboutet, C., Sauzéon, H., Corsini, M. M., Rodrigues, J., Langevin, S., \& N'Kaoua, B. (2010). Performance on a semantic verbal fluency task across time: dissociation between clustering, switching, and categorical exploitation processes. Journal of Clinical and Experimental Neuropsychology, 32(3), 268-80.

Revelle, W. (1979). Hierarchical cluster analysis and the internal structure of tests. Multivariate Behavioral Research, 14, 57-74.

Revelle, W. (2017) psych: procedures for personality and psychological research, Northwestern University, Evanston, Illinois, USA. Retrieved from <https://CRAN.R-project.org/package=psych $>$ Version $=1.7 .8$.

Rosch, E., Mervis, C. B., Gray, W., Johnson, D., \& Boyes-Braem, P. (1976). Basic objects in natural categories. Cognitive Psychology, 8, 382-439.

Ross, N., Medin, D., Coley, J. D., \& Atran, S. (2003). Cultural and experiential differences in the development of folkbiological induction. Cognitive Development, 18(1), 25-47.

Ruff, R. M., Light, R. H., Parker, S. B., \& Levin, H. S. (1997). The psychological construct of word fluency. Brain and Language, 57(3), 394-405.

Sackes, M., Trundle, K. C., \& Flevares, L. M. (2009). Using children's literature to teach standard-based science concepts in early years. Early Childhood Education Journal, 36(5), 415-22.

Snow, C. E., \& Beals, D. E. (2006). Mealtime talk that supports literacy development. New Directions for Child and Adolescent Development, 2006(111), 51-66.

Tan, C. M., Wang, X., \& Zhang, X. (2018). It's all in the stars: The Chinese zodiac and the effects of parental investments on offspring's cognitive and noncognitive skills development. IFPRI Discussion Paper 1708. International Food Policy Research Institute.

Taverna, A. S., Waxman, S. R., Medin, D. L., Moscoloni, N., \& Peralta, O. A. (2014). Naming the living things: linguistic, experiential and cultural factors in Wichí and Spanish speaking children. Journal of Cognition and Culture, 14(3/4), 213-33.

White, T. G., Graves, M. F., \& Slater, W. H. (1990). Growth of reading vocabulary in diverse elementary schools: decoding and word meaning. Journal of Educational Psychology, 82(2), 281-90.

Williams, R. S., Terry, N. P., \& Metzger, I. (2013). Kid categories: a comparison of the category productions of LSES and MSES elementary school children. Communication Disorders Quarterly, 34(2), 71-80.

Winkler-Rhoades, N., Medin, D., Waxman, S. R., Woodring, J., \& Ross, N. O. (2010). Naming the animals that come to mind: effects of culture and experience on category fluency. Journal of Cognition and Culture, 10(1), 205-20.

Wu, C. C., \& Honig, A. S. (2010). Taiwanese mothers' beliefs about reading aloud with preschoolers: findings from the Parent Reading Belief Inventory. Early Child Development and Care, 180(5), 647-69.

Cite this article: McGregor K, Munro N, Chen SM, Baker E, Oleson J (2018). Cultural influences on the developing semantic lexicon. Journal of Child Language 45, 1309-1336. https://doi.org/10.1017/ S0305000918000211 